Jurnal Akuntansi dan Keuangan (JAK)

Volume 6, No. 2 Oktober Tahun 2021

Page: $15-26$

http://ojs.uho.ac.id/index.php/jak-uho/issue/archive

e-ISSN: 2088-4656

\title{
PENGARUH IMPLEMENTASI CORPORATE SOCIAL RESPONSIBILITY TERHADAP KESEJAHTERAAN MASYARAKAT (Studi Kasus Pada PT. Wijaya Karya Bitumen, Pasarwajo)
}

\author{
Husin $^{1}$, Ika Maya Sari², Irmawani Rafiudin ${ }^{3}$ \\ Jurusan Akuntansi Fakultas Ekonomi dan Bisnis Universitas Halu Oleo Kendari \\ Sulawesi Tenggara
}

\begin{abstract}
ABSTRAK
Penelitian ini bertujuan untuk mengetahui dan menganalisis pengaruh implementasi Corporate Social Responsibility terhadap kesejahteraan masyarakat. PT. Wijaya Karya Bitumen bergerak di sektor pertambangan pengolahan aspal. Populasi dalam penelitian ini adalah sebanyak 177 orang. Sampel dalam penelitian ini menggunakan metode slovin, sehingga diperoleh sampel sebanyak 64. Metode analisis data yang digunakan dalam penelitian ini adalah metode analisis deskriptif dan analisis regresi sederhana menggunakan aplikasi SPSS versi 22. Hasil penelitian ini menunjukkan bahwa variabel implementasi Corporate Social Responsbility berpengaruh signifikan terhadap kesejahteraan masyarakat. Hal ini dilihat dari tingkat singnifikansi sebesar $0,000<\alpha=0,05$. Artinya dengan adanya implementasi Corporate Social Responsibility yang dilaksanakan PT. Wijaya Karya Bitumen maka sangat berdampak terhadap kesejahteraan masyarakat.
\end{abstract}

Kata Kunci : Corporate Social Responsbility, Kesejahteraan Masyarakat, Sektor Pertambangan

\section{ABSTRACT}

This research aimed to know and analyze the effect of implementation Corporate Social Responsibility on community welfare. PT Wijaya Karya Bitumen is engaged in the asphalt processing minning sector. The population in this research is 177. The sample in this research use the slovin method, so that to obtain a sample of 64. The data analysis method used this research is descriptive analysis method and simple regression analysis using the application SPSS version 22. The results of this research showed that the variable implementation Corporate Social Responsibility has an effect on community welfare. This can be seen from the significance of $0,000<\alpha=0,05$. This means that the implementation Corporate Social Responsibility of PT Wijaya Karya Bitumen has a huge impact on the community welfare.

Key word: Corporate Social Responsibility, Community Welfare, Minning Sector 
Jurnal Akuntansi dan Keuangan (JAK)

Volume 6, No. 2 Oktober Tahun 2021

Page: $15-26$

http://ojs.uho.ac.id/index.php/jak-uho/issue/archive

e-ISSN: 2088-4656

\section{PENDAHULUAN}

Pada awalnya Corporate Social Responsibility (CSR) merupakan kegiatan yang bersifat suka rela. Namun seiring berjalannya waktu CSR merupakan kegiatan yang wajib diperhatikan oleh perusahaan. Hal ini sesuai dengan Undang-Undang Nomor 40 Tahun 2007 tentang Perseroan terbatas, dan Undang-Undang Nomor 47 Tahun 2012 tentang pertanggungjawaban sosial dan lingkungan perusahaan. Kedua undang-undang tersebut memiliki maksud bahwa perusahaan memiliki tanggung jawab bukan hanya kepada shareholder dan kreditur, melainkan juga kepada masyarakat sekitar. Hal ini dikarenakan keberadaan operasional perusahaaan berdampak langsung maupun tidak langsung terhadap masyarakat sekitar. Sehingga perusahaan diharapkan memiliki tanggung jawab kepada masyarakat dengan memberikan bantuan yang dapat meningkatkan kesejahteraan masayarakat.

Implementasi tanggung jawab sosial (social responsibility) merupakan tahap aplikasi program social responsibility sebagaimana yang telah direncanakan sebelumnya. Manajemen implementasi tanggung jawab sosial perusahaan dapat dilakukan melalui pola charity philanthropy, social activity, dan community development. Implementasi tanggung jawab berbasis charity Philanthropy merupakan kegiatan tanggung jawab sosial bersifat karikatif, jangka pendek insidensial. Pola social activity merupakan strategi pelaksanaan tanggung jawab sosial dengan bantuan jasa untuk meringankan masyarakat. Sementara pola community development mendudukkan stakeholder dalam paradigma common interest.

Tanggung jawab sosial perusahaan diklasifikasikan menjadi tiga yaitu tanggung jawab ekonomi, lingkungan, dan community (masyarakat). Tanggung jawab sosial untuk masyarakat merupakan tanggung jawab yang harus diperhatikan perusahaan. Namun demikian, masih banyak perusahaan yang kurang memperhatikan tanggung jawab sosial tersebut. Adanya perubahan pola pikir masyarakat mengharuskan perusahaan memperhatikan berbagai tanggung jawab sosial yang ada di masyarakat.

Salah satu perusahaan yang telah menjalankan tanggung jawab sosial adalah PT Wijaya Karya Bitumen. PT Wijaya Karya Bitumen merupakan perusahaan milik Negara yang bergerak dalam industri aspal di Pulau Buton. Perusahaan ini melakukan kegiatan Corporate Social Responsibility melalui Program Pengembangan Masyarakat (PPM). PPM tersebut dilaksanakan di daerah sekitar IUP (Izin Usaha Tambang), yakni desa Banabungi, desa Mantowu, dan desa Winning yang disesuikan dengan kondisi perusahaan. PPM tersebut meliputi beberapa bidang yakni, bidang pendidikan, kesehatan, sosial dan budaya, keagamaan, serta lingkungan infrastruktur.

Beberapa program Corporate Social Responsibility (CSR) tersebut sudah dilaksanakan selama 5 tahun dengan realisasi anggaran CSRnya sebagai berikut:

\begin{tabular}{|c|c|c|}
\hline No & Tahun & Anggaran (Rp) \\
\hline 1. & 2015 & 185.000 .000 \\
\hline 2. & 2016 & 264.489 .500 \\
\hline
\end{tabular}


Jurnal Akuntansi dan Keuangan (JAK)

Volume 6, No. 2 Oktober Tahun 2021

Page: $15-26$

http://ojs.uho.ac.id/index.php/jak-uho/issue/archive

e-ISSN: 2088-4656

\begin{tabular}{|l|l|l|}
\hline 3. & 2017 & 267.440 .000 \\
\hline 4. & 2018 & 206.000 .000 \\
\hline 5. & 2019 & 181.845 .420 \\
\hline
\end{tabular}

Sumber: Annual Report PT. Wijaya Karya Bitumen

Berdasarkan tabel tersebut, dapat diketahui bahwa realisasi anggaran CSR setiap tahunnya mengalami perubahan. Hal ini dapat dilihat pada tahun 2015-2017 mengalami peningkatan. Sementara ditahun 2018 dan 2019 mengalami penurunan. Nilai laba bersih perusahaan yang naik turun dapat menjadi penyebab penurunan maupun kenaikan anggaran CSR tersebut.

Berdasarkan uraian pada latar belakang diatas, maka rumusan masalah dalam penelitian yakni "apakah Implementasi Corporate Social Responsibility berpengaruh terhadap Kesejahteraan Masyarakat?”

\section{LANDASAN TEORI DAN HIPOTESIS}

\section{Teori Stakeholder}

Menurut Chariri dan Ghozali (2007:409), dalam teori stakeholder menyatakan bahwa perusahaan bukanlah sebuah entitas yang hanya beroperasi untuk kepentingan sendiri, namun harus memberikan manfaat kepada seluruh stakeholders-nya (pemegang saham, kreditor, konsumen, supplier, pemerintah, masyarakat, dan pihak lain). Dengan demikian, keberadaan suatu perusahaan dipengaruhi oleh dukungan dari kelompok stakeholder-nya. Tujuan utama dari teori stakeholders adalah untuk membantu manajemen perusahaan dalam meningkatkan penciptaan nilai sebagai dampak dari aktivitas-aktivitas yang dilakukan perusahaan serta menimalisir dampak kerugian yang mungkin muncul bagi stakeholder.

Adanya teori stakeholder ini menjadi landasan bahwa perusahaan tidak hanya sekedar bertanggung terhadap para pemilik (shareholder) sebagaimana yang terjadi selama ini, namun bergeser menjadi luas yaitu sampai pada ranah sosial kemasyarakatan (stakeholder), selanjutnya disebut tanggung jawab sosial (social responsibility). Stakeholder merupakan pihak yang mempengaruhi dan dipengaruhi baik secara langsung maupun tidak langsung atas aktivitas serta kebijakan yang diambil dan dilakukan perusahaan. Jika perusahaan tidak memperhatikan stakeholder bukan tidak mungkin akan menuai protes dan dapat mengeliminasi legitimasi stakeholder (Nor Hadi, 2018:146).

\section{Teori Legitimasi}

Teori legitimasi menjelaskan bahwa perusahaan akan terus berupaya dalam memastikan kegiatan operasional dalam bingkai dan norma yang ada dalam masyarakat dimana perusahaan berada, dimana mereka berusaha untuk memastikan bahwa aktivitas mereka (perusahaan) diterima oleh pihak luar sebagai sesuatu yang "sah" (Deegan, 2004). Menurut Ghozali dan Chairiri (2007), hal yang mendasari teori legitimasi adalah adanya "kontrak sosial" yang terjadi antara perusahaan dengan masyarakat dimana 
Jurnal Akuntansi dan Keuangan (JAK)

Volume 6, No. 2 Oktober Tahun 2021

Page: $15-26$

http://ojs.uho.ac.id/index.php/jak-uho/issue/archive

e-ISSN: 2088-4656

perusahaan beroperasi dan menggunakan ekonomi. O'Donovon (2002) dalam Nor Hadi (2018) berpendapat bahwa legitimasi organisasi dapat dilihat sebagai sesuatu yang diberikan masyarakat kepada perusahaan dan sesuatu yang diinginkan atau dicari perusahaan dari masyarakat. Dengan demikian, legitimasi merupakan manfaat atau sumber daya potensial bagi perusahaan untuk bertahan hidup (going concern) yang bersumber dari masyarakat.

\section{Definisi Corporate Social Responsibility}

Johnson (2006) dalam Nor Hadi (2018), mengemukakan bahwa tanggung jawab sosial adalah komitmen perusahaan secara sadar tanpa tekanan untuk menjalankan bisnis dengan berkomitmen secara berkelanjutan, etis, dan berkontribusi secara ekonomi. Lebih lanjut Johnson mengatakan bahwa social responsibility juga dimaksudkan untuk meningkatkan kualitas hidup tenaga kerja (pegawai) beserta keluarganya, serta meningkatkan kesejahteraan bagi masyarakat sekitar dan masyarakat dalam arti luas. Sementara Lako (2011) mengemukakan bahwa tanggung jawab sosial (Corporate Social Responsibility) merupakan bentuk tindakan perusahaan akibat dampak yang ditimbulkan kepada masyarakat dan lingkungan.

\section{Prinsip-Prinsip Corporate Social Responsibility}

Ranah tanggung jawab sosial (social responsibility) mengandung dimensi yang sangat luas dan komplek, dan memiliki interpretasi yang sangat berbeda, terutama jika dikaitkan dengan pemangku kepentingan (stakeholder). Untuk memudahkan pemahaman dan penyederhanaan, Crowther David (2008) dalam Nor Hadi (2018) menguraikan prinsip-prinsip tanggung jawab sosial (social responsibility) menjadi tiga, yaitu :
1) Sustainability
2) Accountability
3) Transparancy

\section{Implementasi Corporate Social Responsibility}

Implementasi corporate social responsibility merupakan tahap aplikasi program social responsibility. Perusahaan dalam mencapai tujuan tanggung jawab sosial melakukan berbagai pendekatan yang dijadikan sebagai indikator dalam mengimplementasikan praktik tanggung jawab sosial (Nor Hadi, 2018:258). Berbagai pendekatan tersebut yaitu :

1) Implementasi berbasis Charity Philanthropy

2) Implementasi berbasis Social Activity

3) Implementasi berbasis Community Development

\section{Definisi Kesejahteraan Masyarakat}

Masyarakat merupakan sekumpulan orang yang hidup bersama dalam suatu wilayah atau daerah yang diatur dengan aturan (norma) tertentu. Edi Suharto (2009) mengartikan masyarakat dalam arti sempit dan dalam arti luas. Dalam arti sempit masyarakat disebut komunitas atau community. Sedangkan dalam arti luas, masyarakat 
Jurnal Akuntansi dan Keuangan (JAK)

Volume 6, No. 2 Oktober Tahun 2021

Page: $15-26$

http://ojs.uho.ac.id/index.php/jak-uho/issue/archive

e-ISSN: 2088-4656

menunjuk pada interaksi kompleks sejumlah orang yang memiliki kepentingan dan tujuan bersama meskipun tidak bertempat tinggal dalam satu wilayah geografis tertentu.

Menurut Rudy Badrudin (2012), kesejahteraan masyarakat adalah suatu kondisi yang memperlihatkan tentang keadaan kehidupan masyarakat yang dapat dilihat dari standar kehidupan masyarakat. Kesejahteraan masyarakat dapat juga dikatakan sebagai kesejahteraan sosial.

\section{Indikator Kesejahteraan Masyarakat}

Kesejahteraan menunjuk keadaan yang lebih baik, kondisi manusia dimana orang-orangnya didalam keadaan makmur, dalam keadaan sehat dan damai. Menurut Hermanita (2013) indikator kesejahteraan masyarakat, antara lain:

1) Jumlah dan pemerataan pendapatan.

2) Pendidikan

3) Kesehatan

4) Fasilitas Pedesaan

\section{Hipotesis Penelitian}

Berdasarkan latar belakang dan beberapa hasil penelitian yang berkaitan, maka rumusan hipotesis dalam penelitian ini yaitu : Implementasi Corporate Social Responsibility berpengaruh signifikan terhadap kesejahteraan masyarakat.

\section{METODE PENELITIAN}

Penelitian ini dilakukan di PT. Wijaya Karya Bitumen yang berlokasi di Kecamatan Pasarwajo, Kabupaten Buton. Objek dari penelitian yang dilakukan adalah implementasi Corporate Sosial Responsibility (CSR) terhadap Kesejahteraan Masyarakat.

Populasi dalam penelitian ini adalah masyarakat yang bertempat tinggal di wilayah Izin Usaha Pertambangan (IUP) yang mendapat program Corporate Social Responsibility, yaitu desa Banabungi, desa Mantowu, dan desa Winning. Populasi dalam penelitian ini berjumlah 177. Penentuan sampel dalam penelitian ini menggunakan metode slovin dengan tingkat kepercayaan 90\% dan tingkat error $10 \%$, sehingga diperoleh sampel sebanyak 64 .

Jenis data dalam penelitian ini menggunakan data kualitatif dan data kuantitatif. Data kualitatif berupa sejarah perusahaan, visi misi, dan struktur perusahaan. Sementara data kuantitatif berupa jawaban responden atas kuesioner yang diukur dengan menggunakan skala likert.

Sumber data yang digunakan adalah data primer dan data sekunder. Metode pengumpulan data yang dilakukan dalam penelitian ini yaitu : 1) Kuesioner adalah teknik pengumpulan data menggunakan pernyataan tertulis kepada responden. 2) Wawancara adalah pengumpulan data dengan melakukan interaksi atau hubungan langsung dengan responden atau dengan sebagian pihak perusahaan yang mempunyai 
Jurnal Akuntansi dan Keuangan (JAK)

Volume 6, No. 2 Oktober Tahun 2021

Page: $15-26$

http://ojs.uho.ac.id/index.php/jak-uho/issue/archive

e-ISSN: 2088-4656

wewenang dalam memberikan informasi data perusahaan. 3) Dokumentasi yaitu pengambilan data yang telah didokumentasikan oleh pihak PT. Wijaya Karya Bitumen.

Metode analisis data yang digunakan dalam penelitian ini adalah metode analisis deskriptif dan analisis regresi sederhana. Analisis deskriptif bertujuan untuk menginterprestasikan mengenai distribusi frekuensi jawaban responden. Analisis regresi sederhana digunakan dengan bantuan software SPSS versi 22. Teknik ini digunakan untuk menguji signifikan pengaruh implementasi Corporate Social Responsibility (CSR) terhadap kesejahteraan masyarakat. Hubungan antara variabel tersebut dapat digambarkan dalam persamaan sebagai berikut:

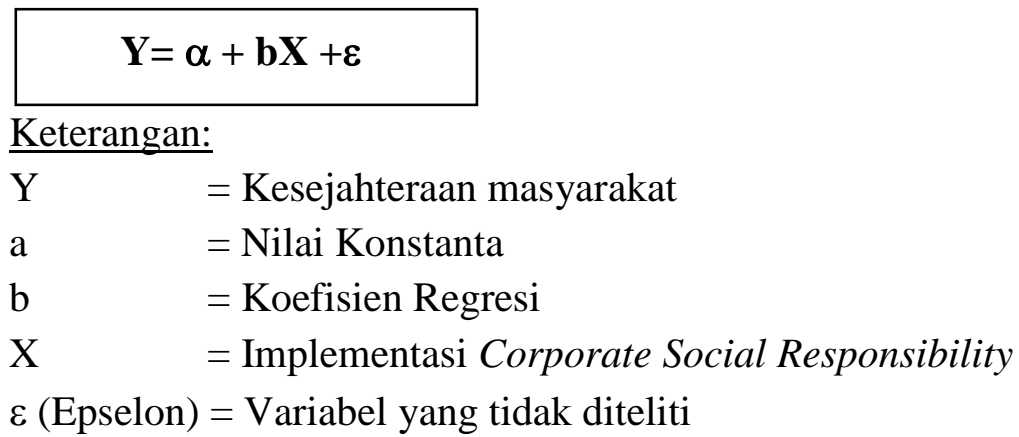

\section{HASIL DAN PEMBAHASAN}

\section{Hasil Penelitian}

\section{Pengujian Kualitas Data}

Uji kualitas data atas kuesioner yang digunakan yaitu uji validitas dan reliabilitas. Berdasarkan hasil uji validitas dan uji reliabilitas diperoleh bahwa keseluruhan item dan indikator dari variabel peneltian ini menunjukkan hasil yang valid dan reliable. Keputusan ini diambil karena nilai korelasi pearson > 0,30 dengan tingkat signifikansi < 0,05 dan nilai koefisien korelasi dari hasil cronbach alpha > 0,60.

\section{Uji Asumsi Klasik}

\section{a. Uji Normalitas}

Uji normalitas bertujuan untuk menguji apakah dalam sebuah model regresi variabel pengganggu atau residual memiliki distribusi normal. Jika data menyebar disekitar diagonal dan mengikuti arah garis diagonal, maka model regresi memenuhi asumsi normalitas. Jika data menyebar jauh dari garis diagonal dan atau tidak mengikuti arah garis diagonal, maka model regresi tidak memenuhi asumsi normalitas. Kemudian pada histogram tampak residual terdistribusi secara normal ditunjukkan dengan pola yang berbentuk simetris tidak melenceng ke kanan atau ke kiri. 
Jurnal Akuntansi dan Keuangan (JAK)

Volume 6, No. 2 Oktober Tahun 2021

Page: $15-26$

http://ojs.uho.ac.id/index.php/jak-uho/issue/archive

e-ISSN: 2088-4656
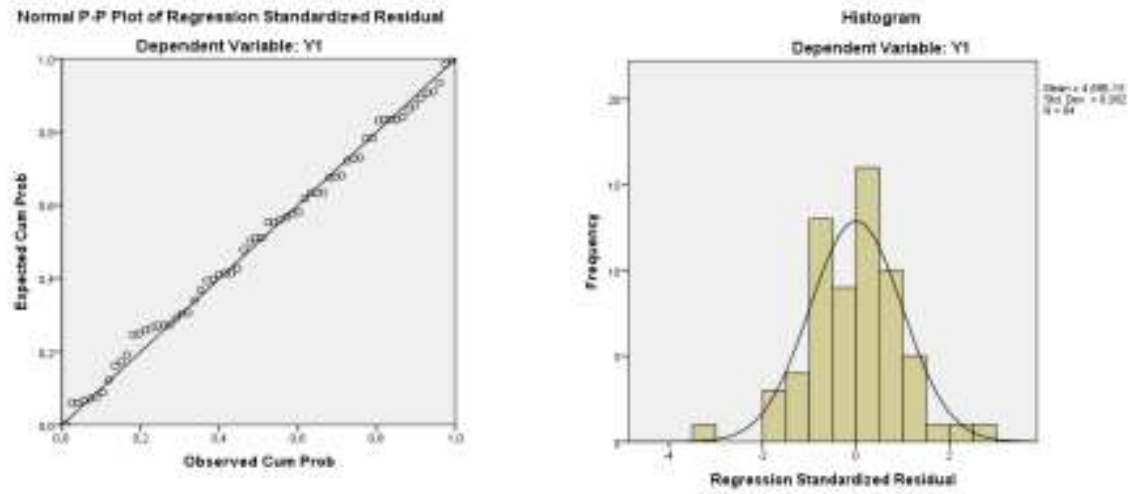

Sumber: Data Primer Diolah 2021

\section{b. Uji Heterokedastisitas}

Uji heterokedastisitas bertujuan untuk menguji apakah dalam model regresi terjadi ketidaksamaan varian dari residual pengamatan satu ke pengamatan yang lain. Uji heterokedastisitas dilakukan melalui scatter plot (diagram pencar). Homokedastisitas dari variabel bebas terhadap variabel terikat terpenuhi apabila nilai residual dan nilai prediksinya tidak membentuk pola tertentu. Hasil analisis data menunjukkan diagram pancar yang dihasilkan sebagai berikut:

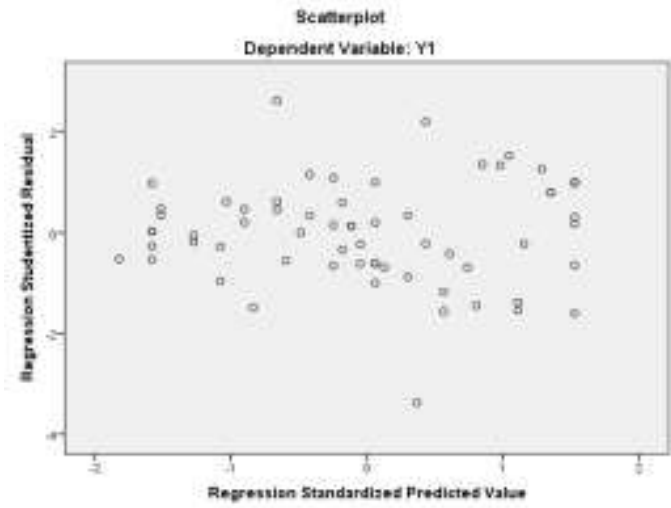

Sumber: Data Primer Diolah 2021

\section{c. Uji Autokelasi}

Uji autokorelasi dilakukan untuk menguji apakah suatu model regresi linier terdapat korelasi antara residual (kesalahan pengganggu) dari suatu periode ke periode lainnya. Model regresi yang baik adalah yang bebas dari autokorelasi atau korelasi serial. Deteksi adanya autokerelasi dapat dilihat dari nilai Durbin Watson (D-W) sebagai berikut: 
Jurnal Akuntansi dan Keuangan (JAK)

Volume 6, No. 2 Oktober Tahun 2021

Page: $15-26$

http://ojs.uho.ac.id/index.php/jak-uho/issue/archive

e-ISSN: 2088-4656

Model Summary ${ }^{b}$

\begin{tabular}{|c|c|c|c|c|c|c|c|c|c|c|}
\hline \multirow[t]{2}{*}{ Model } & \multirow[t]{2}{*}{$\mathrm{R}$} & \multirow{2}{*}{$\begin{array}{c}\mathrm{R} \\
\text { Square }\end{array}$} & \multirow{2}{*}{$\begin{array}{l}\text { Adjusted } \\
\text { R Square }\end{array}$} & \multirow{2}{*}{$\begin{array}{c}\text { Std. } \\
\text { Error } \\
\text { of the } \\
\text { Estimat } \\
\mathrm{e}\end{array}$} & \multicolumn{5}{|c|}{ Change Statistics } & \multirow{2}{*}{$\begin{array}{c}\text { Durbin } \\
- \\
\text { Watson }\end{array}$} \\
\hline & & & & & $\begin{array}{c}\mathrm{R} \\
\text { Square } \\
\text { Change }\end{array}$ & $\begin{array}{c}\text { F } \\
\text { Chan } \\
\text { ge }\end{array}$ & df1 & df2 & $\begin{array}{l}\text { Sig. F } \\
\text { Change }\end{array}$ & \\
\hline 1 &, $745^{\mathrm{a}}$ & ,554 & ,547 & ,31292 &, 554 & $\begin{array}{r}77,1 \\
47\end{array}$ & 1 & 62 &, 000 & 1,788 \\
\hline
\end{tabular}

a. Predictors: (Constant), X1

b. Dependent Variable: Y1

Sumber: Data Primer Diolah 2021

Berdasarkan output summary sebagaimana pada angka Durbin-Watson (D_W) adalah 1,788, dimana angka tersebut berada diantara -4 sampai +4 yang berarti tidak terjadi autokorelasi.

\section{Analisis Regresi Linear Sederhana}

Data hasil penelitian ini diolah menggunakan metode regresi linear berganda dengan bantuan IBM SPSS 22. Hal ini dilakukan untuk mengetahui apakah terdapat pengaruh dari variabel implementasi Corporate Social Responsibility terhadap kesejahteraan masyarakat dan dari hasil pengolahan diperoleh nilai sebagaimana yang tercantum dalam tabel hasil estimasi linear sederhana Implementasi Corporate Social Responsibility terhadap Kesejahteraan Masyarakat sebagai berikut:

\section{Coefficients $^{\mathrm{a}}$}

\begin{tabular}{|c|c|c|c|c|c|c|c|c|c|c|}
\hline \multirow[t]{2}{*}{ Model } & \multicolumn{2}{|c|}{$\begin{array}{l}\text { Unstandardize } \\
\text { d Coefficients }\end{array}$} & \multirow{2}{*}{\begin{tabular}{|c}
$\begin{array}{c}\text { Standar } \\
\text { dized } \\
\text { Coeffic } \\
\text { ients }\end{array}$ \\
Beta
\end{tabular}} & \multirow[t]{2}{*}{$\mathrm{t}$} & \multirow[t]{2}{*}{ Sig. } & \multicolumn{3}{|c|}{ Correlations } & \multicolumn{2}{|c|}{$\begin{array}{l}\text { Collinearit } \\
\text { y Statistics }\end{array}$} \\
\hline & B & $\begin{array}{l}\text { Std. } \\
\text { Error }\end{array}$ & & & & $\begin{array}{l}\text { Zero- } \\
\text { order }\end{array}$ & $\begin{array}{c}\text { Parti } \\
\text { al }\end{array}$ & Part & $\begin{array}{l}\text { Toler } \\
\text { ance }\end{array}$ & VIF \\
\hline $\begin{array}{l}\text { (Con } \\
\text { stant) }\end{array}$ & ,909 & ,373 & & $\begin{array}{r}2,43 \\
5\end{array}$ & ,018 & & & & & \\
\hline $\mathrm{X} 1$ & ,758 & ,086 & ,745 & $\begin{array}{r}8,78 \\
3\end{array}$ & ,000 & ,745 & ,745 & ,745 & $\begin{array}{r}1,00 \\
0\end{array}$ & $\begin{array}{r}1,00 \\
0\end{array}$ \\
\hline
\end{tabular}

\section{a. Dependent Variable: Y1}

Sumber: Data Primer Diolah 2021

Berdasarkan hasil koefisien regresi pada tabel di atas maka dapat diperoleh persamaan sebagai berikut: 
Jurnal Akuntansi dan Keuangan (JAK)

Volume 6, No. 2 Oktober Tahun 2021

Page: $15-26$

http://ojs.uho.ac.id/index.php/jak-uho/issue/archive

e-ISSN: 2088-4656

$$
Y=0,909+0,758 X+\varepsilon
$$

Berdasarkan tabel estimasi linear sederhana tersebut maka dapat dikemukakan bahwa koefisien bernilai positif yaitu sebesar 0,758 , hal ini menunjukkan bahwa jika variabel implementasi Corporate Social Responsibility memiliki nilai konstan atau sama dengan nol, maka kesejahteraan masyarakat akan tetap sebesar 0,758 atau 75,8\%.

\section{Uji Hipotesis}

Variabel implementasi Corporate Social Responsibility (CSR) berpengaruh signifikan terhadap kesejahteraan masyarakat, dapat diketahui dengan menggunakan uji t, dan koefisien determinasi yang disajikan dalam tabel berikut:

\begin{tabular}{|c|c|c|c|c|}
\hline Variabel & $\mathrm{t}_{\text {-hitung }}$ & $\mathrm{t}_{\text {-tabel }}$ & Sig. & R.Square \\
\hline $\mathrm{X}$ & 8,783 & 1,998 & 0,000 & 0,554 \\
\hline
\end{tabular}

Sumber: Data Primer Diolah 2021

Pengujian hipotesis dapat dilakukan dengan membandingkan $t_{\text {hitung }}$ dengan $t_{\text {tabel }}$ dan nilai $\mathrm{t}$-sig dengan $\alpha: 0,05$. Apabila $\mathrm{t}_{\text {-hitung }}>\mathrm{t}_{\text {-tabel }}$ atau $\mathrm{t}_{\text {-sig }}<\alpha: 0,05$. Berdasarkan tabel diatas, menunjukkan bahwa t-hitung yaitu sebesar 8,783>t-tabel yaitu 1,998 tingkat signifikansi sebesar $0,000<\alpha=0,05$, maka dari itu hasil pengujian tersebut dapat disimpulkan bahwa implementasi Corporate Social Responsibility berpengaruh signifikan terhadap kesejahteraan masyarakat disekitar PT. Wijaya Karya Bitumen.

Koefisien determinasi dimaksudkan untuk mengetahui besarnya kontribusi implementasi Corporate Social Responsibility terhadap kesejahteraan masyarakat, dengan melihat nilai koefisen determinasinya $\left(\mathrm{R}^{2}\right)$. Berdasarkan tabel tersebut diketahui besarnya $\mathrm{R}^{2}$ ( $R$-Square $)=0,554$. Hal ini menunjukkan bahwa besarnya pengaruh variabel implementasi Corporate Social Responsibility (X) terhadap kesejahteraan masyarakat (Y) adalah sebesar 55,4 \%. Hal ini berarti ada variabel lain atau variabel epsilon $(\varepsilon)$ sebesar $44,6 \%$ yang mempengaruhi variabel $\mathrm{Y}$ namun tidak diukur dalam penelitian ini.

\section{Pembahasan}

Pembahasan hasil penelitian ini menjelaskan mengenai variabel implementasi Corporate Social Responsibility yang mempengaruhi kesejahteraan masyarakat. Dimana dikemukakan sebelumnya bahwa variabel implementasi Corporate Social Responsibility berpengaruh signifikan terhadap kesejahteraan masyarakat.

Berdasarkan hasil pengujian hipotesis menunjukkan bahwa variabel implementasi Corporate Social Responsibility berpengaruh signifikan terhadap kesejahteraan masyarakat. Artinya Corporate Social Responsibility yang diberikan PT. Wijaya Karya Bitumen memiliki dampak terhadap kesejahteraan masyarakat. Hal ini menunjukkan bahwa mayoritas responden yang dalam hal ini masyarakat yang mendapat CSR setuju bahwa Corporate Social Responsibility membantu masyarakat. 
Jurnal Akuntansi dan Keuangan (JAK)

Volume 6, No. 2 Oktober Tahun 2021

Page: $15-26$

http://ojs.uho.ac.id/index.php/jak-uho/issue/archive

e-ISSN: 2088-4656

Keberadaan perusahaan ditengah lingkungan masyarakat berpengaruh langsung maupun tidak langsung terhadap lingkungan eksternal (community). Eksistensi perusahaan ditengah lingkungan masyarakat berperan merubah dua kondisi, yaitu positif (positive externalities) dan negatif (negative externalities). Positive externalities, perusahaan memberi manfaat peningkatan ekonomi sosial dan lingkungan dalam bentuk peningkatan kesejahteraan, infrastruktur, tata sosial, ilmu pengetahuan dan teknologi. Dampak negatif (negative externalities), keberadaan perusahaan memunculkan ketimpangan sosial, diskriminasi, pencemaran lingkungan, global warming dan sejenisnya.

Hasil penelitian ini menunjukkan dengan adanya Corporate Social Responsibility dilakukan oleh PT. Wijaya Karya Bitumen maka akan meningkatkan tingkat kesejahteraan masyarakat. Artinya program Corporate Social Responsibility yang dilakukan PT. Wijaya Karya Bitumen berdasarkan indikator charity philanthropy, social activity, dan community development mempengaruhi kesejahteraan masyarakat disekitar perusahaan.

Berdasarkan hasil analisis deskriptif variabel implementasi Corporate Social Responsibility, rata-rata skor jawaban yang paling dominan adalah indikator charity philanthropy sebesar 4,43. Hal ini artinya mayoritas responden setuju bahwa perusahaan merupakan pihak yang selalu berderma setiap saat. Hal tersebut dilihat dari kegiatan yang dilaksanakan perusahaan seperti sembako pasar murah, menurut tanggapan responden dengan adanya pasar murah masyarakat memperoleh sembako dengan harga terjangkau. Selain kegiatan pasar murah, kegiatan charity phlanthropy yang dilaksanakan rutin setiap tahun yaitu pemberian daging kurban kepada masyarakat.

Jika dilihat dari rata-rata tingkat capaian responden variabel implementasi Corporate Social Responsibility berada pada kategori sangat baik yaitu 4,30, ini menunjukkan bahwa secara keseluruhan responden sangat setuju bahwa implementasi Corporate Social Responsibility berpengaruh terhadap kesejahteraan masyarakat. Artinya dengan adanya Corporate Social Responsibility selain sebagai kegiatan wajib yang dilaksanakan perusahaan dalam upaya pembangunan berkelanjutan, kegiatan ini dapat menguntungkan perusahaan berupa kepercayaan masyarakat (legitimasi).

Hasil penelitian ini sejalan dengan penelitian yang dilakukan Linda Astuti (2017), Wewen Rio Wilyandri (2017), dan Lena Epriliana (2017) menyatakan bahwa program Corporate Social Responsibility berpengaruh positif terhadap kesejahteraan masyarakat. Hal ini berarti bahwa program Corporate Social Responsibility dapat meningkatkan kesejahteraan masyarakat. 
Jurnal Akuntansi dan Keuangan (JAK)

Volume 6, No. 2 Oktober Tahun 2021

Page: $15-26$

http://ojs.uho.ac.id/index.php/jak-uho/issue/archive

e-ISSN: 2088-4656

\section{KESIMPULAN, IMPLIKASI, KETERBATASAN, REKOMENDASI}

\section{Kesimpulan}

Berdasarkan hasil penelitian mengenai Pengaruh Implementasi Corporate Social Responsibility PT. Wijaya Karya Bitumen terhadap kesejahteraan masyarakat diperoleh kesimpulan bahwa Implementasi Corporate Social Responsibility berpengaruh signifikan terhadap kesejahteraan masyarakat. Hal ini berarti bahwa dengan adanya implementasi Corporate Social Responsibility yang dilaksanakan PT. Wijaya Karya Bitumen maka sangat berdampak terhadap kesejahteraan masyarakat. Corporate Social Responsibility yang diberikan perusahaan berupa bantuan dibidang pendidikan, kesehatan, keagamaan, dan fasilitas pedesaan.

\section{Implikasi}

Hasil penelitian ini diharapkan dapat memberikan masukan, bahan acuan dan dapat bermanfaat untuk sarana informasi tambahan terkait implementasi Corporate Social Responsibility terhadap kesejahteraan masyarakat.

\section{Keterbatasan}

Penelitian ini hanya terbatas pada satu variabel dependen saja yaitu kesejahteraan masyarakat, diharapkan untuk peneliti selanjutnya menambah variabel dependen lainnya.

\section{Rekomendasi}

Adapun rekomendasi yang diajukan oleh penulis dari penelitian yang telah dilakukan yaitu:

1. Bagi Perusahaan

- Implementasi Corporate Social Responsibility perusahaan perlu melibatkan seluruh aspek masyarakat agar program-program Corporate Social Responsibility benar-benar bermanfaat bagi masyarakat dan lingkungan.

- Meskipun Corporate Social Responsibility yang dilakukan oleh perusahaan telah dapat meningkatkan kesejahteraan masyarakat, namun diperlukan inovasi dalam pelaksanaanya.

2. Bagi Peneliti Selanjutnya

Disarankan untuk mengembangkan penelitian ini dengan mempertimbangkan variabel-variabel lain diluar dari variabel yang telah digunakan dalam penelitian ini, seperti corporate social issues, corporate relation program, dan lain sebagainya.

\section{Daftar Pustaka}

Astuti, Linda. 2017. Pengaruh Corporate Social Responsibility (CSR) Terhadap Kesejahteraan Masyarakat Di Sekitar PT. Panca Usaha Palopo Plywood. Jurnal ISSN 2339-1502, 4 (1):37-51. Diakses 18 Agustus 2020.

Epriliana, Lina. 2017. Implementasi Corporate Social Responsibility Terhadap Kesejahteraan Masyarakat (Studi Kasus Multi Mart Batanghari Lampung Timur). 
Jurnal Akuntansi dan Keuangan (JAK)

Volume 6, No. 2 Oktober Tahun 2021

Page: $15-26$

http://ojs.uho.ac.id/index.php/jak-uho/issue/archive

e-ISSN: 2088-4656

Fakultas Ekonomi dan Bisnis Islam Institut Agama Islam Negeri Metro. Diakses 20 Agustus 2020.

Badrudin, Rudy. 2012. Ekonomika Otonomi Daerah. Yogyakarta: UPP STIM YKPN.

Chariri dan Ghozali, I. 2007. Teori Akuntansi. Semarang: Badan Penerbit UNDIP.

Deegan, C. 2004. Financial Accounting Theory. Sydney: McGraw-Hill.

Hadi, Nor. 2018. Corporate Social Responsibility.Yogyakarta: Expert.

Hermanita. 2013. Perekonomian Indonesia. Yogyakarta: Idea Press.

Lako, Andreas. 2011. Dekonstruksi CSR dan Reformasi Paradigma Bisnis dan Akuntansi. Jakarta: Erlangga.

Laporan Tahunan/Annual Report PT. Wijaya Karya Bitumen Tahun 2015, diakses 30 Agustus 2020.

Laporan Tahunan/Annual Report PT. Wijaya Karya Bitumen Tahun 2016, diakses 30 Agustus 2020.

Laporan Tahunan/Annual Report PT. Wijaya Karya Bitumen Tahun 2017, diakses 30 Agustus 2020.

Laporan Tahunan/Annual Report PT. Wijaya Karya Bitumen Tahun 2018, diakses 30 Agustus 2020.

Laporan Tahunan/Annual Report PT. Wijaya Karya Bitumen Tahun 2019, diakses 30 Agustus 2020.

Pemerintah Indonesia. (2007). Undang-Undang Republik Indonesia Nomor 40 Tahun 2007 tentang Perseroan Terbatas. Diakses 20 Agustus 2020.

Pemerintah Indonesia. Undang-Undang Nomor 47 Tahun 2012 Tentang Pertanggungjawaban sosial dan Lingkungan Perusahaan.

Suharto, Edi. 2009. Pekerjaan Sosial di Dunia Industri Memperkuat CSR (Corporate Social Responsibility). Bandung: Alfabeta.

Wilyandri, Wewen Rio. 2017. Pengaruh Implementasi Tanggung Jawab Sosial Perusahaan/Corporate Social Responsibility (CSR) Terhadap Kesejahteraan Hidup Masyarakat. Jurnal ISSN: 1693-6876 Journal Administrasi dan Manajemen, 10 (5): 670-677. 